\title{
Neuregulin-Dependent Regulation of Fast-Spiking Interneuron Excitability Controls the Timing of the Critical Period
}

\author{
Yu Gu, ${ }^{1}$ Trinh Tran, ${ }^{2}$ Sachiko Murase, ${ }^{1}{ }^{\oplus}$ Andrew Borrell, ${ }^{1}$ Alfredo Kirkwood, ${ }^{2}$ and Elizabeth M. Quinlan ${ }^{1}$ \\ ${ }^{1}$ Neuroscience and Cognitive Science Program, Department of Biology, University of Maryland, College Park, Maryland 20742, and ${ }^{2}$ Mind/Brain Institute, \\ Johns Hopkins University, Baltimore, Maryland 21218
}

\begin{abstract}
Maturation of excitatory drive onto fast-spiking interneurons (FS INs) in the visual cortex has been implicated in the control of the timing of the critical period for ocular dominance plasticity. However, the mechanisms that regulate the strength of these synapses over cortical development are not understood. Here we use a mouse model to show that neuregulin (NRG) and the receptor tyrosine kinase erbB4 regulate the timing of the critical period. NRG1 enhanced the strength of excitatory synapses onto FS INs, which inhibited ocular dominance plasticity during the critical period but rescued plasticity in transgenics with hypoexcitable FS INs. Blocking the effects of endogenous neuregulin via inhibition of erbBs rescued ocular dominance plasticity in postcritical period adults, allowing recovery from amblyopia induced by chronic monocular deprivation. Thus, the strength of excitation onto FS INs is a key determinant of critical period plasticity and is maintained at high levels by NRG- erbB4 signaling to constrain plasticity in adulthood.
\end{abstract}

Key words: critical period; fast-spiking interneurons; neuregulin; ocular dominance plasticity; parvalbumin

\section{Significance Statement}

Despite decades of experimentation, the mechanisms by which critical periods of enhanced synaptic plasticity are initiated and terminated are not completely understood. Here we show that neuregulin (NRG) and the receptor tyrosine kinase erbB4 determine critical period timing by controlling the strength of excitatory synapses onto FS INs. NRG1 enhanced excitatory drive onto fast spiking interneurons, which inhibited ocular dominance plasticity in juveniles but rescued plasticity in transgenics with hypoexcitable FS INs. Blocking the effects of endogenous neuregulin via inhibition of erbBs rescued ocular dominance plasticity in adults, allowing recovery from amblyopia induced by chronic monocular deprivation. Thus, in contrast to prevailing views of the termination of the critical period, active maintenance of strong excitation onto FS INs constrains plasticity in adults.

\section{Introduction}

The shift in the ocular dominance of binocular neurons induced by monocular deprivation (MD) is the canonical model of receptive field plasticity confined to a developmental critical period. Research performed primarily in mice is beginning to reveal the mechanisms by which critical period plasticity is regulated. It is well appreciated that the perisomatic inhibition mediated by fastspiking interneurons (FS INs) exerts powerful control over the

Received Nov. 24, 2015; revised July 29, 2016; accepted Aug. 1, 2016.

Author contributions: A.K. and E.M.Q. designed research; Y.G., T.T., S.M., and A.B. performed research;Y.G., T.T., S.M., A.B., A.K., and E.M.Q. analyzed data; E.M.Q. wrote the paper.

This work was supported by NIH Grants R01EY016431 (E.M.Q.) and R01EY025922 (E.M.Q. and A.K.).

The authors declare no competing financial interests.

Correspondence should be addressed to either of the following: Elizabeth M. Quinlan at the above address.

E-mail: equinlan@umd.edu; or Alfredo Kirkwood at the above address. E-mail: kirkwood@jhu.edu.

DOI:10.1523/JNEUROSCI.4242-15.2016

Copyright $\odot 2016$ the authors $\quad 0270-6474 / 16 / 3610285-11 \$ 15.00 / 0$ excitability and plasticity of downstream pyramidal neurons. Accordingly, enhancing the output of FS INs can enable plasticity in precritical period mice, whereas decreasing the output can reactivate plasticity in adults (Huang et al., 1999; Fagiolini and Hensch, 2000; Di Cristo et al., 2007; Kuhlman et al., 2013; Krishnan et al., 2015). However, ocular dominance plasticity persists after the developmental maturation of perisomatic inhibition (Sawtell et al., 2003; Pham et al., 2004; Lehmann and Löwel, 2008; Huang et al., 2010), suggesting that regulatory control is upstream of inhibitory output.

Alternatively, we have proposed that the maturation of excitatory drive onto FS INs determines the timing of the critical period (Huang et al., 2010; Gu et al., 2013). Importantly, several proteins that regulate synaptic strength and/or number, including neuregulin (NRG) and neuronal activity-regulated pentraxin (NARP), are highly enriched at excitatory synapses onto FS INs. Signaling mediated by NRGs has been implicated in the matura- 
A

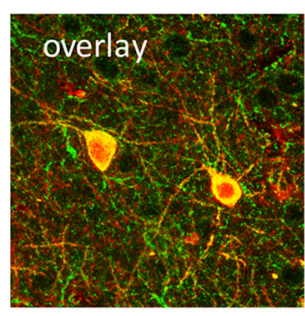

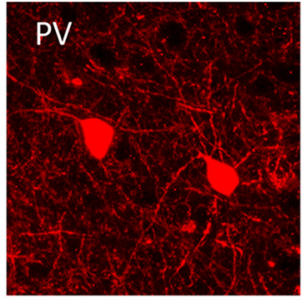

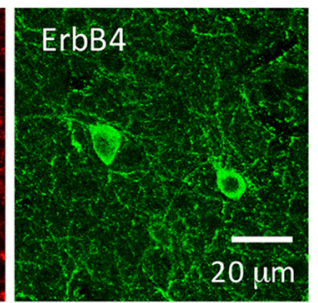

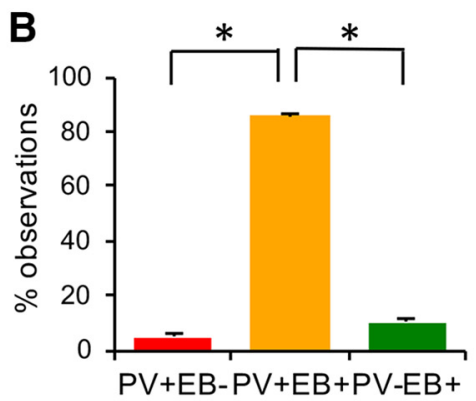

F
C
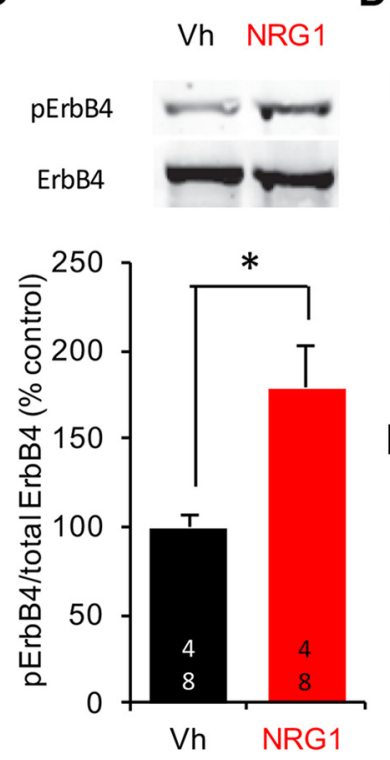

Vehicle

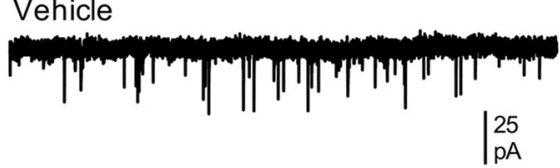

NRG1

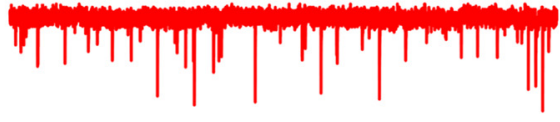

$\mathbf{E}$

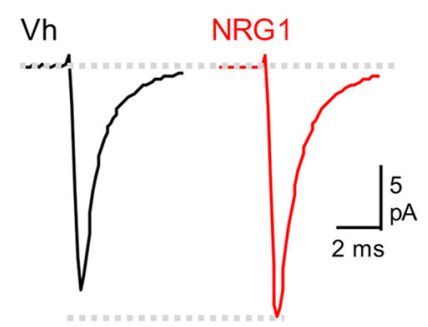

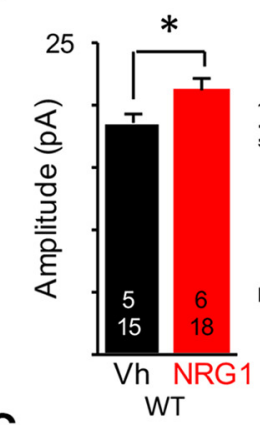

G

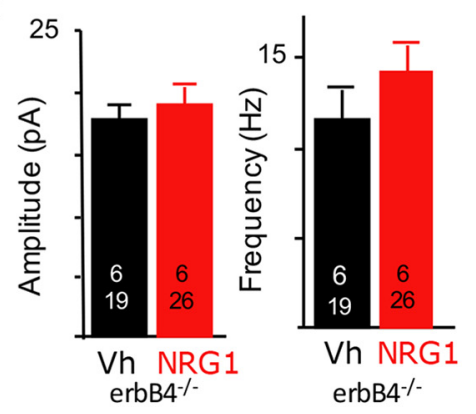

Figure 1. NRG1 activates cortical erbB4 receptors and increases excitation onto PV + interneurons. A, Immunohistochemical colocalization of ErbB4 receptor (green) and PV (red) in P30 visual cortex. B, Quantification of colocalization as a percentage of all observations of fluorescence: $\mathrm{PV}^{+} \mathrm{Erb}^{-}, 4.54 \pm 0.99 \% ; \mathrm{PV}^{+} \mathrm{EB}^{+}, 85.58 \pm 0.82 \% ; \mathrm{PV}^{-} \mathrm{EB}^{+}, 9.88 \pm 1.39 \% . n=250$ neurons from 18 slices from six subjects. One-way ANOVA, $F_{(4,17)}=1718.07, p<0.0001 ;{ }^{*} p<0.01$, Tukey-Kramer post hoc test. C, Single intraperitoneal injection of NRG1 (10 ng/kg in $0.9 \%$ sodium chloride solution) induced a significant increase in phosphorylation of erbB4 receptors in primary visual cortex. Inset, Representative example of immunoblot for phospho-erbB4 and total erbB4. ${ }^{*} p<0.05, t$ test. $\boldsymbol{D}$, Representative examples of 2 s current traces of pharmacologically isolated mEPSCs in PV interneurons from layer $2 / 3$ of visual cortex slices after vehicle (black) or NRG1 (10 ng/kg; i.p.; 2 times per day for 3 d; red) treatment. $\boldsymbol{E}$, Average of $\mathrm{mEPS}(\mathrm{s}$ recorded in both conditions. I solated $\mathrm{mEPS}(\mathrm{s}$ were averaged first by neuron and second by condition. $\boldsymbol{F}$, NRG 1 treatment increased the amplitudes (left; ${ }^{*} p=0.035$, $t$ test) but not the frequencies (right; $t$ test, $p=0.201$ ) of mEPSCs in PV INs. $G$, Absence of response to NRG1 in PV-erbB4 ${ }^{-1-}$ mice. The numbers of mice, neurons are indicated within the columns. Vh, Vehicle.

tion of excitation onto FS INs, and dysregulation of NRG1 is a risk factor for schizophrenia (Rico and Marín, 2011; Penzes et al., 2013). NRGs are synthesized as transmembrane precursors, requiring proteolytic cleavage to release a soluble peptide containing an epidermal growth factor (EGF)-like sequence that activates the receptor tyrosine kinase erbB4 (Mei and Nave, 2014). ErbB4 is a primary target of NRG1, and erbB4 expression is highly enriched in parvalbumin ${ }^{+}\left(\mathrm{PV}^{+}\right)$interneurons of prefrontal cortex, hippocampus and amygdala (Fazzari et al., 2010; Neddens and Buonanno, 2010; Bean et al., 2014; Lu et al., 2014).

Small NRG1-derived recombinant peptides corresponding to the soluble EGF domain common to all NRG1 splice variants have been used to elucidate the role of erbB4 activation in vivo. A single application of a NRG1 peptide acutely regulates the intrinsic properties and ion channel distribution of erbB4 ${ }^{+}$interneurons (Janssen et al., 2012; Li KX et al., 2012; Mitchell et al., 2013). In contrast, repeated delivery of a NRG1 peptide is thought to recruit ErbB4 to the synapse, enabling a tyrosine kinasedependent stabilization of PSD-95 and an increase in AMPAR- mediated EPSC amplitudes (Li et al., 2007; Ting et al., 2011). Accordingly, repeated delivery of a NRG1 peptide increases the amplitudes of mEPSCs recorded in FS INs, accompanied by an increase in the amplitudes of AMPAR-mediated excitatory currents and an increase in GluR1 surface expression (Abe et al., 2011). Blocking endogenous NRG signaling, through pharmacological inhibition or genetic ablation of ErbB4, reverses these effects. Specifically, inhibition of erbB4 with a function-blocking peptide reduces the number and size of excitatory synapses on cultured GABAergic interneurons (Ting et al., 2011). Longerterm manipulations of NRG/erbB signaling may also impact the number of excitatory synapses onto FS INs. Indeed, treatment with a NRG1 peptide induces a delayed increase in the frequencies of mEPSCs in FS INs, and a decrease in mEPSC frequencies after erbB4 deletion is revealed only in adults (Abe et al., 2011; Yang et al., 2013).

Changes in FS IN excitability mediated by NRG-erbB4 signaling impact the plasticity of excitatory synapses onto downstream pyramidal neurons. NRG1 treatment of hippocampal slices sup- 


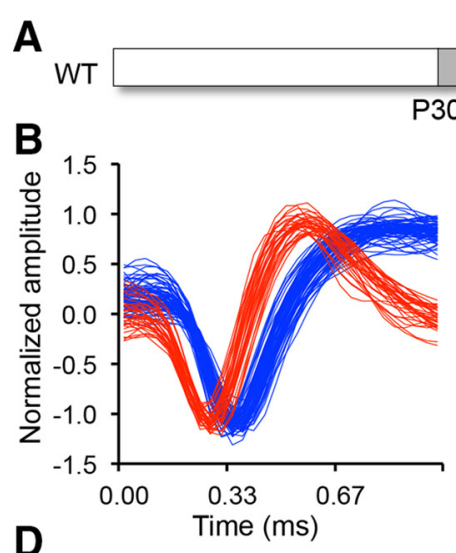

NRG1

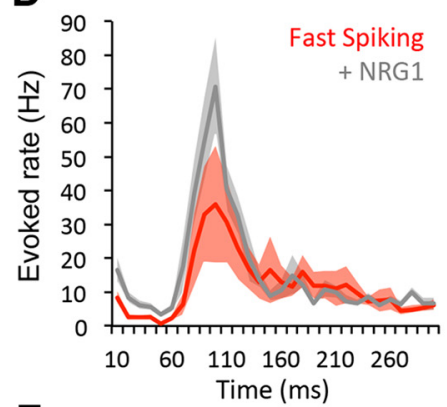

$\mathbf{F}$
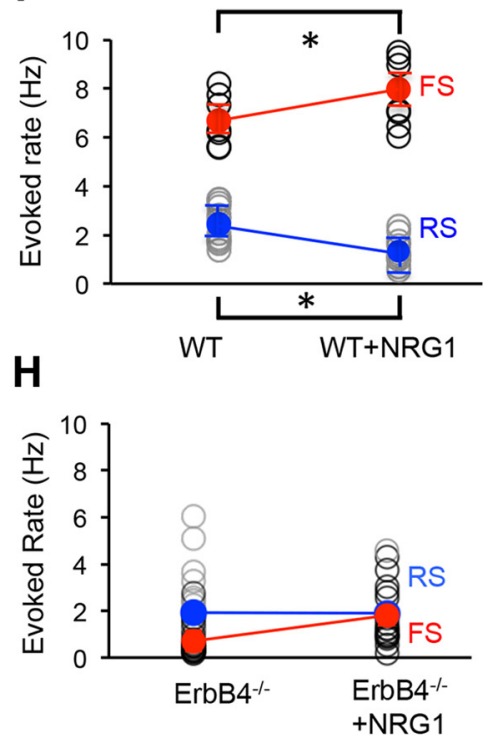

C 0.1

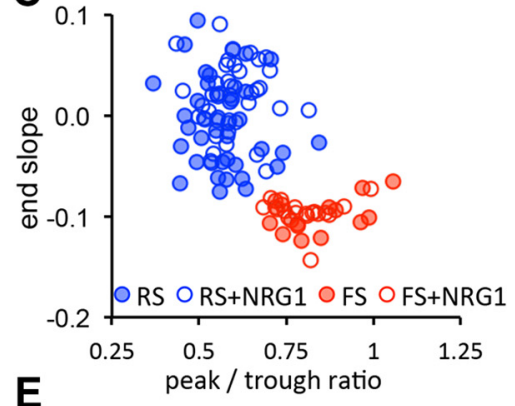

E

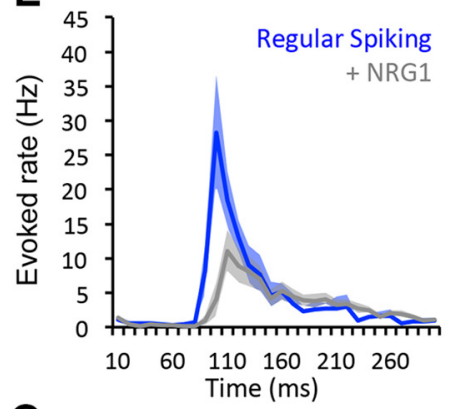

G
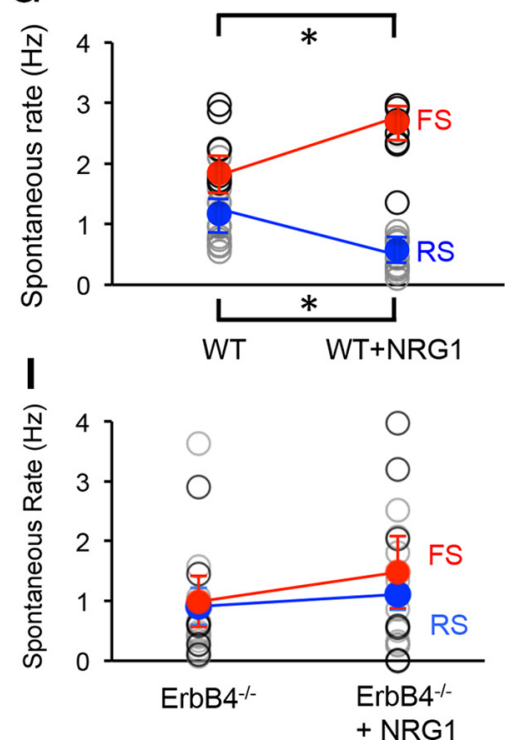

Figure 2. NRG1 increases excitability of FS INs in vivo. $\boldsymbol{A}$, Experimental schematic. NRG1 treatment was initiated on P30. $\boldsymbol{B}, \boldsymbol{C}$, The treatment does not change the characteristics of single-unit waveforms $(\boldsymbol{B})$ or the sorting into two clusters based on waveform characteristics ( $\boldsymbol{C}$; red, FS; blue, RS). $\boldsymbol{D}, \boldsymbol{E}$, Average \pm SEM poststimulus time histograms for fast-spiking (red) and regular-spiking (blue) neurons in binocular visual cortex before and after NRG1 treatment. Activity was evoked with $100 \%$ contrast, 0.05 cycles $/{ }^{\circ}$ gratings reversing at $1 \mathrm{~Hz} . \boldsymbol{F}, \mathbf{G}$, Significant difference in average visually evoked $(\boldsymbol{F})$ and spontaneous $(\boldsymbol{G})$ spike rates in FS (red) and RS (blue) neurons before and after treatment. $\boldsymbol{H}, \boldsymbol{I}$, Absence of response to NRG1 in PV-erbB4 ${ }^{-1-}$ mouse. Activity was averaged over $500 \mathrm{~ms}$. Lines connect group averages. ${ }^{*} p<0.05, t$ test.

presses LTP of Schaffer collaterals in hippocampus and inhibits activity-dependent enhancement of synaptic NMDAR currents (Pitcher et al., 2011; Tamura et al., 2012). Similarly, transgenic deletion of erbB4 in $\mathrm{PV}^{+}$interneurons in the amygdala increases LTP of inputs onto pyramidal neurons and impairs fear conditioning (Lu et al., 2014). Together, this suggests that excitatory synapses onto FS INs are the major cellular target of NRG-ErbB4 signaling, and this pathway exerts powerful control over FS IN excitability and plasticity of downstream pyramidal neurons.
Here we show that manipulation of this pathway exerts bidirectional control over the strength of excitatory drive onto FS INs in the visual cortex, allowing for reversible regulation of the critical period for ocular dominance plasticity throughout life.

\section{Materials and Methods}

Wild-type and NARP ${ }^{-1-}$ mice (Kirkpatrick et al., 2000), equal numbers of males and females, of C57BL/6, 129/SVJII mixed genetic background were raised on a $12 \mathrm{~h}$ light/dark cycle, with food and water available ad libitum. PVCre/ErbB4 ${ }^{-1-}$ mice, obtained by crossing mice expressing Cre recombinase from the PV locus $\left(P v a 1 b^{t m 1(c r e) A r b r}\right)$ with mice expressing a floxed ErbB4 allele, were a generous gift from Dr. A. Buonanno (NIH-NICHD, Bethesda, MD; Shamir et al., 2012). All procedures conformed to the guidelines of the U.S. Department of Health and Human Services and the Institutional Animal Care and Use Committees of the University of Maryland and Johns Hopkins University. MD was performed under ketamine/xylazine anesthesia $(50 \mathrm{mg} / 10 \mathrm{mg}$ / $\mathrm{kg}$, i.p.). The margins of the upper and lower lids of one eye were trimmed and sutured together. The animals were returned to their home cages and disqualified in the event of suture opening or infection. For dark exposure (DE), animals were placed in a light-tight dark room, with animal care provided under far red illumination.

Immunohistochemistry. Postnatal day 30 (P30) mice were perfused transcardially with $4 \%$ paraformaldehyde. Brains were incubated in $4 \%$ paraformaldehyde overnight, $30 \%$ sucrose for $1 \mathrm{~d}$ at $4^{\circ} \mathrm{C}$, and cryoprotectant for $1 \mathrm{~d}$ at $4^{\circ} \mathrm{C}$. Forty-micrometer coronal slices were prepared on a freezing microtome (Leica). Sections were incubated in a blocking solution (4\% normal goat serum in PBS) for $30 \mathrm{~min}$ at room temperature before incubation with primary antibodies (mouse monoclonal antiparvalbumin, 1:1000; Millipore) or rabbit polyclonal anti-ErbB4 (1:500; a gift from Dr. A. Buonanno) in a blocking solution overnight at $4^{\circ} \mathrm{C}$, followed by secondary antibodies (Alexa 555 goat anti-mouse IgG, 1:300; Invitrogen) or biotinylated goat anti-rabbit IgG (1:300; Vector Laboratories) at room temperature for $4 \mathrm{~h}$. ErbB4 was visualized after incubation in Alexa 488-conjugated streptavidin (1:300; Invitrogen) at room temperature for $4 \mathrm{~h}$. Slices were washed with PBS three times for $10 \mathrm{~min}$ between each step. $Z$-stack of eight images of V1b at $1 \mu \mathrm{m}$ intervals of $1024 \times 1024$ pixels were acquired on a Zeiss LSM710 confocal microscope with a $40 \times$ lens.

Quantitative immunoblots. P30 mice received a single intraperitoneal injection of NRG1 (10 ng/kg in $0.9 \%$ sodium chloride solution) or vehicle 90 min before dissection. Primary visual cortices were dissected bilaterally as described previously (Scott et al., 2010) under isoflurane anesthesia ( $4 \%$ in $100 \% \mathrm{O}_{2}$; flow rate, $800 \mathrm{cc} / \mathrm{min}$ ). Tissue was immediately homogenized with a sonic dismembrator (model 100; Thermo Fisher Scientific) in ice-cold lysis buffer (150 mM NaCl, 1\% NP-40, 50 $\mathrm{mm}$ Tris-HCl, $\mathrm{pH}$ 8.0) containing a protease inhibitor mixture (Roche). Protein concentrations were determined using the BCA protein assay kit 
(Thermo Fisher Scientific). Sample concentrations were normalized in $4 \times$ SDS loading buffer and boiled for $5 \mathrm{~min}$. Fifty micrograms of total protein per lane were separated on polyacrylamide gels, followed by transfer to nitrocellulose. Nitrocellulose was blocked with $4 \%$ nonfat dry milk in PBS for $30 \mathrm{~min}$ and incubated with rabbit polyclonal pTyr-1284 erbB4 antibody (1:500 in blocking solution; Abcam) overnight at $4^{\circ} \mathrm{C}$. Alexa 488 -conjugated goat anti-rabbit IgG was used as a secondary antibody (1:500 in blocking solution, incubated at room temperature for $4 \mathrm{~h}$; Life Technologies). Membranes were washed three times for 10 min with Tris-buffered saline with $0.05 \%$ Tween 20 between each step. The proteins were detected with Typhoon TRIO Variable Mode Imager (GE Healthcare) and analyzed with ImageQuant TL (GE Healthcare). The membranes were stripped with $100 \mathrm{~mm}$ glycine- $\mathrm{HCl}$ ( $\mathrm{pH} 3.0)$ and reprobed with a rabbit polyclonal anti-erbB4 antibody.

Slice electrophysiology. Visual cortical slices were prepared as described previously (Guo et al., 2012). Slices (300 $\mu \mathrm{m}$ thick) were cut in ice-cold dissection buffer containing (in $\mathrm{mM}$ ) 212.7 sucrose, $5 \mathrm{KCl}, 1.25 \mathrm{NaH}_{2} \mathrm{PO}_{4}, 10 \mathrm{MgCl}_{2}$, $0.5 \mathrm{CaCl}_{2}, 26 \mathrm{NaHCO}_{3}$, and 10 dextrose, bubbled with $95 \% \mathrm{O}_{2} / 5 \% \mathrm{CO}_{2}$, pH 7.4. Slices were transferred to normal artificial CSF (ACSF) for at least $1 \mathrm{~h}$ before recording. Normal ACSF was similar to the dissection buffer except that sucrose was replaced by $124 \mathrm{~mm} \mathrm{NaCl}, \mathrm{MgCl}_{2}$ was lowered to $1 \mathrm{~mm}$, and $\mathrm{CaCl}_{2}$ was raised to $2 \mathrm{~mm}$. Visualized whole-cell recordings were made from layer 2/3 neurons with glass pipettes $(4-6 \mathrm{M} \Omega$ ). Data were filtered at 2 $\mathrm{kHz}$ and digitized at $5-10 \mathrm{kHz}$ using Igor Pro (Wavemetrics). Only cells with membrane potentials more negative than $-65 \mathrm{mV}$, series resistance $<20 \mathrm{M} \Omega$, and input resistance larger than $100 \mathrm{M} \Omega$ were studied. Cells were excluded if input resistance changed $>20 \%$ over the entire experiment. Miniature EPSC recordings were performed with an intracellular solution containing (in mM) 130 Cs-gluconate, $8 \mathrm{KCl}, 1$ EGTA, 10 HEPES, 4 (Na)ATP, and 5 QX-314 (pH adjusted to 7.25 with $\mathrm{CsOH}$, 280-290 mOsm) under voltage clamp (vehicle, $-70 \mathrm{mV})$. TTX $(1 \mu \mathrm{M})$, APV $(100 \mu \mathrm{M})$, and picrotoxin $(10 \mu \mathrm{M})$ were included in the bath. Events were detected and analyzed using Mini Analysis (Synaptosoft).

In vivo electrophysiology was performed under light isoflurane anesthesia ( $\sim 1.5 \%$ in $100 \% \mathrm{O}_{2}$ via modified nose cone). The dura covering binocular visual cortex was exposed through a hole $(\sim 3 \mathrm{~mm}$ diameter $)$ in the skull. The exposed brain was kept moist with artificial CSF (in mM $124 \mathrm{NaCl}, 5 \mathrm{KCl}, 1.25 \mathrm{NaH}_{2} \mathrm{PO}_{4}, 1 \mathrm{MgCl}_{2}, 2 \mathrm{CaCl}_{2}, 26 \mathrm{NaHCO}_{3}$, and 10 dextrose, bubbled with $95 \% \mathrm{O}_{2} / 5 \% \mathrm{CO}_{2}$, $\mathrm{pH} 7.4$ ) in a room with supplemental humidity (ZD300Y0; Zenith). Subjects were retained in a stereotax in a darkened room (without visual stimulation) between measurements. Body temperature was maintained at $37^{\circ} \mathrm{C}$ via a circulating water heating pad (T/PUMP; Gaymar Industries), monitored with a rectal probe (BAT-12; Sensortek). A broadband signal was collected from the lateral aspect (binocular region) of the primary visual cortex [site of the largest ipsilateral eye visually evoked potential (VEP), typically $3 \mathrm{~mm}$ lateral to the intersection of lambda and the midline], with a tungsten microelectrode $(0.5 \mathrm{M} \Omega)$ relative to a ground screw in the frontal bone.

A $50 \mathrm{~Hz}$ low-pass filter was used to isolate VEPs in response to $1 \mathrm{~Hz}$ reversals of $100 \%$ contrast gratings $\left(0.04\right.$ cycles $/{ }^{\circ}$ and $40 \mathrm{~cd} / \mathrm{m}^{2}$ luminosity) presented on a computer monitor $25 \mathrm{~cm}$ from the eyes. VEPs were averaged in synchrony with the visual stimulus using OpenEX software (TDT). A bandpass filter $(700-7000 \mathrm{~Hz})$ was used to isolate multiunit activity, which was sorted into single units based on waveform shape and principal component analysis (OpenEx software; TDT). Individual waveforms were aligned by the most negative point, and amplitudes were normalized from -1 to 1 . Single units recorded from layer $2 / 3$ of binocular visual cortex of head-fixed mice sorted into two clusters based on waveform characteristics (the height of the positive peak relative to the initial negative trough and the slope of the waveform $0.5 \mathrm{~ms}$ after the initial trough), representing fast-spiking (presumptive PV interneurons) and regular-spiking (RS; predominantly pyramidal neurons; after Niell and Stryker, 2008) neurons. Spontaneous firing rates were measured in response to $100 \mathrm{~s}$ of blank screen. One hertz reversals of $100 \%$ contrast gratings were presented at nine orientations ranging from $0^{\circ}$ (vertical) to $180^{\circ}$. Evoked spiking rates are reported in response to presentation of the visual stimulus in the preferred orientation.

The recombinant human NRG1- $\beta 1 /$ HRG1- $\beta 1$ EGF domain $(7.5 \mathrm{kDa}$; R\&D Systems), corresponding to residues $176-246$ of the soluble EGF domain of heregulin $\beta 1$ common to all NRG1 splice variants, was dissolved in 100\% saline. PD158780 (Tocris) was dissolved in 10\% Tween $80,20 \%$ DMSO, and $70 \%$ saline.

Statistics. An unpaired two-tailed $t$ test was used to determine statistical significance between two experimental groups. A one-way ANOVA was used to determine the statistical significance between three or more independent experimental groups, followed by a subsequent TukeyKramer honestly significant difference post hoc test for pairwise comparisons, when appropriate. A Kolmogorov-Smirnov test was used to determine the statistical significance between the distributions of two independent data sets. In all cases, the sample size $(n)$ used for statistical comparison equals the number of subjects.

\section{Results}

\section{NRG1 inhibits ocular dominance plasticity during the critical period}

The receptor tyrosine kinase erbB4 is a primary target of NRG signaling in the brain and is highly enriched in $\mathrm{PV}^{+}$interneurons of prefrontal cortex, hippocampus, and amygdala (Fazzari et al., 2010; Neddens and Buonanno, 2010; Bean et al., 2014; Lu et al., 2014). To determine the distribution of this signaling pathway in the mouse visual cortex, we performed immunohistochemistry for erbB4 and parvalbumin, the calcium-binding protein enriched in FS INs in the cortex. Immunoreactivity for erbB4 was highly colocalized with parvalbumin in the visual cortex of postnatal day 30 mice $(\mathrm{P} 30$; percentage of observations: $\mathrm{PV}^{+} \mathrm{EB}^{+}, 85.58 \pm 0.82 \%$; $\mathrm{PV}^{+} \mathrm{EB}^{-}$, $4.54 \pm 0.99 \% ; \mathrm{PV}^{-} \mathrm{EB}^{+}, 9.88 \pm-1.39 \% ; 250$ cells from 18 slices; six subjects; Fig. $1 A, B)$. Furthermore, peripheral administration of a 71 
A
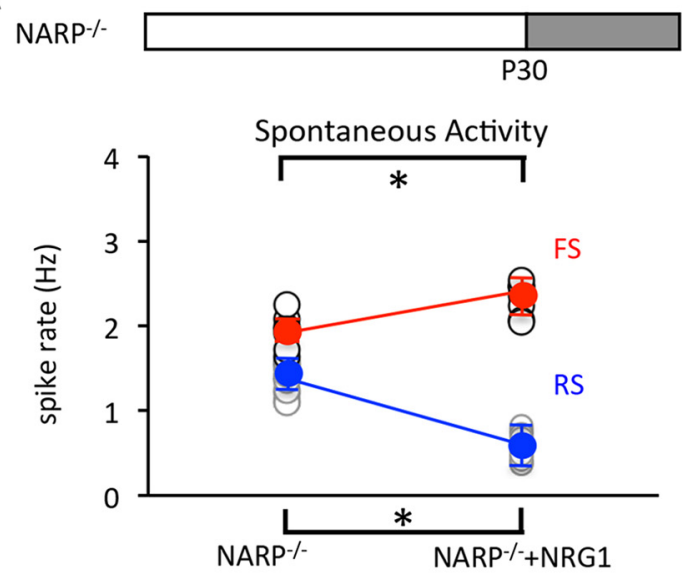

B
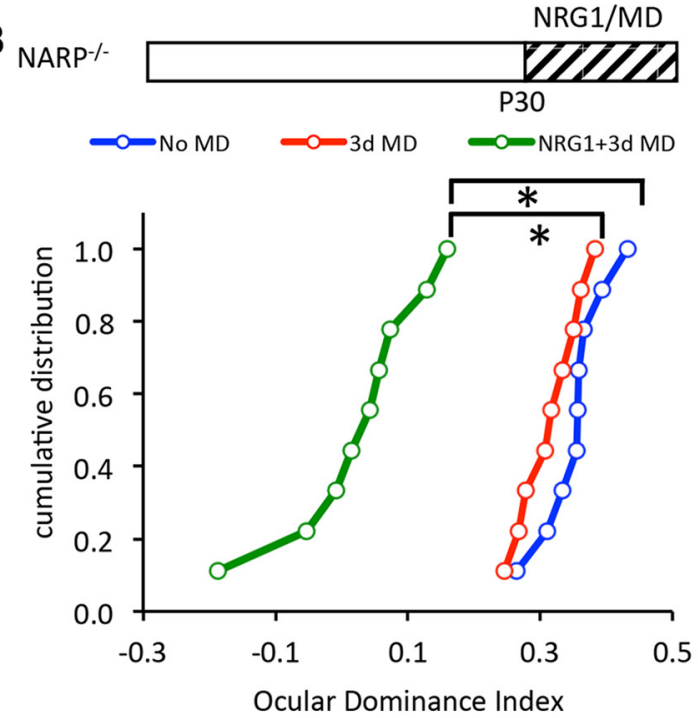

C

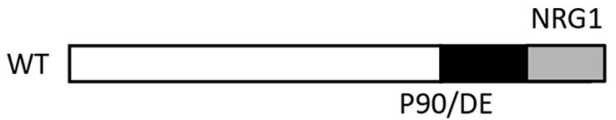

Spontaneous Activity
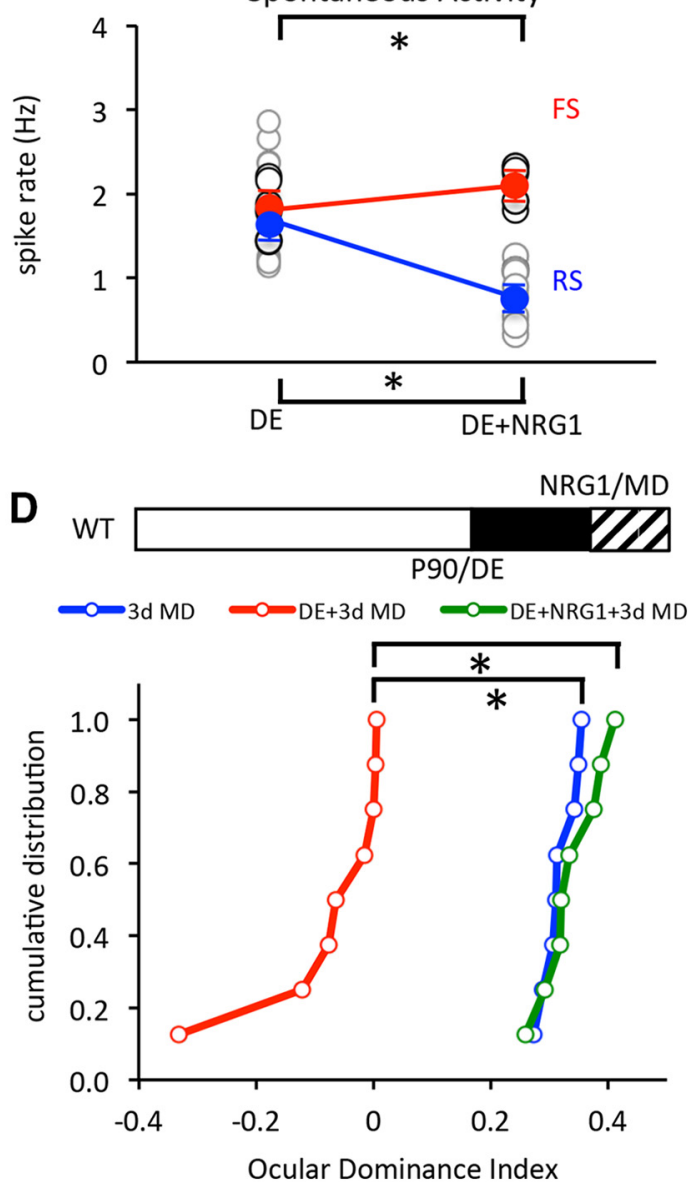

Figure 4. NRG1 treatment in NARP ${ }^{-1-}$ and dark-exposed mice. $A$, Experimental schematic. NRG1 treatment was initiated at P30 in NARP ${ }^{-1-}$ mice. Spontaneous spiking rates were increased in FS INs (red) and decreased in RS neurons (blue) after the treatment. Lines connect group averages ${ }^{*} p<0.05, t$ test. $\boldsymbol{B}$, Experimental schematic. NRG1 treatment was initiated at P30 with concurrent monocular deprivation ( $3 \mathrm{~d}$ ) in NARP ${ }^{-1-}$ mice. Cumulative distributions of ODI. NRG1 enabled a shift in ocular dominance in response to MD (green). Kruskal-Wallis test, $\mathrm{H}(2)=18.38$, ${ }^{*} p<0.001$. C, Experimental schematic. Ten days of dark exposure (from P90 to P100) was followed by NRG1 treatment (from P100 to P103). Spontaneous firing rates were increased in FS INs (red) and decreased in RS neurons (blue) after the treatment. Lines connect group averages. ${ }^{*} p<0.05, t$ test. $D$, Experimental schematic. NRG1 treatment was initiated at P100 with concurrent monocular deprivation (3 d) after DE (from P90 to P100). Cumulative distributions of ODI are shown. NRG1 treatment inhibited ocular dominance plasticity in DE adults (red). ${ }^{*} p<0.001$, Kruskal-Wallis test, $H(2)=15.77$.

amino acid $(7.5 \mathrm{kDa})$ peptide corresponding to residues $176-246$ of the soluble EGF domain of NRG-1- $\beta 1$ (hereafter called NRG1; 10 $\mathrm{ng} / \mathrm{kg}$, i.p.) significantly increased the phosphorylation of erbB4 receptors in visual cortex (Fig. 1C). To determine the effect of repeated delivery of the NRG1 peptide on the strength of excitatory synapses onto FS INs, whole-cell recordings of pharmacologically isolated mEPSCs were performed in slices of visual cortex prepared from G42 mice in which the expression of GFP is restricted to FS basket cells (Taniguchi et al., 2013). Systemic administration of NRG1 (10 ng/kg, i.p., two times per day for $3 \mathrm{~d}$ ) to P30 wild-type mice significantly increased the amplitudes, but not the frequencies, of mEPSCs onto PV interneurons (Fig. $1 D-F$ ). To confirm that these responses to NRG1 are mediated by erbB4 receptors on cortical FS INs, we repeated these experiments in transgenic mice with a conditional deletion of erbB4 restricted to $\mathrm{PV}+$ interneurons (PV-erbB4 ${ }^{-1-}$; Shamir et al., 2012). The frequency of mEPSCs onto FS INs was significantly reduced in these mice. In addition, the regulation of mEPSC amplitudes by NRG1 treatment was absent in PV-erbB4 ${ }^{-1-}$ mice (Fig. 1G).
To determine whether NRG1 can be used to control excitation of FS INs in vivo, NRG1 was delivered to wild-type mice at the peak of the critical period (P30; $10 \mathrm{ng} / \mathrm{kg}$, i.p., two times per day for $3 \mathrm{~d}$ ). Single units recorded from layer $2 / 3$ of binocular visual cortex of head-fixed mice were sorted into two clusters based on waveform characteristics, representing FS (presumptive PV interneurons) and RS (predominantly pyramidal neurons; after Niell and Stryker, 2008) neurons. NRG1 treatment did not impact the waveform characteristics or the clustering of units based on waveform parameters [Fig. $2 A, B$; FS IN, $n=16,6$; +NRG1, $n=18,6$; RS, $n=40,6$; +NRG1, $n=37,6$ (neurons, mice)]. However, NRG1 treatment significantly increased the excitability of FS INs (average \pm SEM evoked, $6.58 \pm 0.35 ;+\mathrm{NRG1}, 7.67 \pm$ 0.46 ; spontaneous, $2.15 \pm 0.17$; +NRG1, $2.56 \pm 0.19)$ and decreased the excitability of RS neurons (evoked, $2.39 \pm 0.21$; + NRG1, $1.30 \pm 0.14$; spontaneous, $0.99 \pm 0.13$; +NRG1, $0.44 \pm$ 0.07; Fig. $2 C-G)$. Importantly, conditional deletion of erbB4 restricted to $\mathrm{PV}+$ interneurons significantly reduced the excitability of FS INs in the P30 visual cortex. Furthermore, the 
regulation of neuronal excitability by NRG1 treatment was absent in PVerbB4 $^{-1-}$ mice (average \pm SEM FS evoked: $0.71 \pm 0.16, n=17,3$; +NRG1: $1.79 \pm 1.05, n=3,3$; spontaneous: $0.99 \pm$ $0.43, n=6,3 ;+\mathrm{NRG} 1: 1.48 \pm 0.61, n=7$, 3; or RS evoked: $1.94 \pm 0.37, n=19,3$; +NRG1: $1.90 \pm 0.3, n=14,3$; spontaneous: $0.91 \pm 0.13, n=16,3$; +NRG1: $1.10 \pm 0.26, n=10$; Fig. $2 H, I)$.

To determine how enhancing the excitability of FS INs impacted ocular dominance plasticity, we examined the effect of NRG1 treatment on the response to concurrent brief ( $3 \mathrm{~d}$ ) monocular deprivation at the peak of the critical period (P30; Fig. 3A). VEPs were recorded in layer $2 / 3$ of the binocular region of the deprived visual cortex in response to contralateral (deprived) and ipsilateral (nondeprived) eye stimulation (Fig. 3B). Brief MD induces a robust shift in ocular dominance at this age, revealed by a significant decrease in the VEP ocular dominance index $[\mathrm{ODI}=($ contralateral eye VEP ipsilateral eye VEP $) /(\mathrm{C}+\mathrm{I})]$. Treatment with NRG1 inhibited the shift in ocular dominance in response to brief $\mathrm{MD}$ $\left[{ }^{*} \mathrm{H}(2)=11.94, p<0.01\right.$, Kruskal-Wallis test, $n=6$ per condition; Fig. $3 C$ ]. This suggests that the NRG1-dependent increase in the excitability of FS INs induced a precocious closure of the critical period of ocular dominance plasticity.

\section{NRG1 enhancement of FS IN excitability rescues ocular dominance plasticity in NARP ${ }^{-/-}$mice}

We recently demonstrated that a reduction in excitatory drive onto FS INs, mediated by transgenic deletion of NARP, inhibited the initiation of the critical period for ocular dominance plasticity (Gu et al., 2013). To ask whether enhancing excitation onto FS INs can rescue this deficit, $\mathrm{NARP}^{-1-}$ mice were treated with NRG1. Single-unit recordings in layer $2 / 3$ of the binocular region of primary visual cortex demonstrate that the hypoexcitability of FS INs and the hyperexcitability of RS neurons in NARP ${ }^{-/-}$mice are reversed by NRG1 treatment (spontaneous firing rates, FS: $\mathrm{NARP}^{-/-}, 1.82 \pm 0.11 ;+\mathrm{NRG} 1,2.14 \pm 0.07 ; n=7$; RS: $\mathrm{NARP}^{-1-}, 1.82 \pm 0.17$; +NRG1, $0.91 \pm 0.08 ; n=7$; Fig. $4 A$ ). Furthermore, NRG1 treatment rescued ocular dominance plasticity in NARP ${ }^{-1-}$ mice, revealed by the significant shift in the ODI induced by brief concurrent $\mathrm{MD}\left[{ }^{*} \mathrm{H}(2)=18.38, p<0.001\right.$, Kruskal-Wallis test, $n=9$ per condition; Fig. $4 B]$. The ability to rescue the phenotype of the NARP ${ }^{-/-}$mouse with NRG1 suggests that these two signaling pathways independently regulate excitation onto FS INs.

\section{NRG1 reverses reactivation of critical period by dark exposure}

The reduction in the excitability of RS neurons of the visual cortex over development contribute to the decline in ocular dominance plasticity with age (Takesian and Hensch, 2013). However, we have previously shown that robust ocular dominance plasticity can be reactivated in the adult mouse visual cortex after complete visual deprivation through dark exposure (He et al., 2007;
B

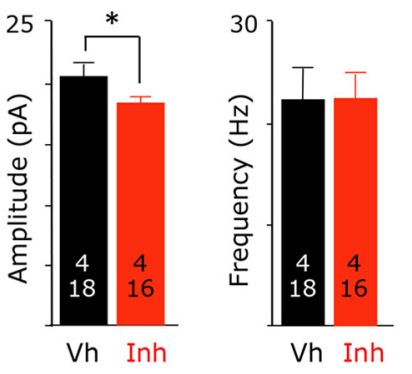

D

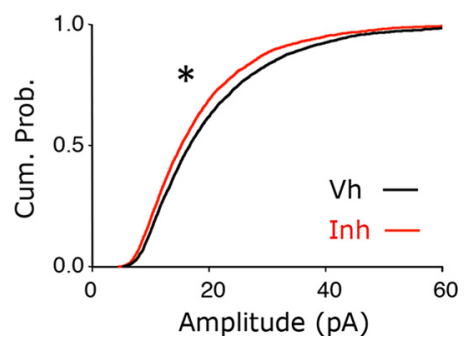

Figure 5. ErbB inhibition reduces excitation onto PV+ interneurons. $\boldsymbol{A}$, Representative examples of $2 \mathrm{~s}$ current traces of (he frequency (Right, $p=0.971, t$ test) of the mEPSCs. The numbers of mice, neurons are indicated within the columns. $D$, Significant difference in the cumulative distribution of $\mathrm{mEPSC}$ amplitudes in vehicle-treated (black) versus erbB inhibitortreated (red; ${ }^{*} p<0.001$, Kolmogorov-Smirnov test) mice. Vh, Vehicle.

Montey and Quinlan, 2011; Eaton et al., 2016). Single unit recordings from layer 2.3 of the primary visual cortex were used to ask if dark exposure regulates the strength of excitation onto FS INs. Ten days of dark exposure initiated in adulthood (P90) significantly decreased the excitability of FS INs and increased the excitability of RS neurons (spontaneous firing rates, FS: DE, $1.74 \pm 0.07, n=7$; RS: DE, $1.22 \pm 0.04, n=7$; Fig. $4 C$ ). To ask whether NRG1 could reverse the effects of DE, NRG1 treatment was initiated at P97, coincident with the last $3 \mathrm{~d}$ of dark exposure. NRG1 significantly increased the excitability of FS INs (+NRG1, $2.11 \pm 0.07$; Fig. $4 C$, red) and decreased excitability of RS neurons (+NRG1, $0.48 \pm 0.04$; Fig. $4 C$, blue) in DE visual cortex. To ask how the increase in FS IN excitability impacted the reactivation of ocular dominance plasticity by dark exposure, darkexposed adults received NRG1 treatment with concurrent brief (3 d) monocular deprivation. NRG1 prevented the induction of ocular dominance plasticity in dark-exposed adults [blue, MD; red, $\mathrm{DE}+\mathrm{MD}$; green, $\mathrm{DE}+\mathrm{NRG} 1+\mathrm{MD} ;{ }^{\star} \mathrm{H}(2)=15.77, p<$ 0.001 , Kruskal-Wallis test, $n=8$ per condition; Fig. $4 D$ ]. Together, this suggests that dark exposure in adults may enable ocular dominance plasticity by decreasing the strength of excitation onto FS INs, and reversing this effect with NRG1 is sufficient to disable this plasticity.

Inhibition of ErbB4 reactivates the critical period in adults To examine the contribution of excitation onto FS INs in controlling the expression of ocular dominance plasticity in adults, we inhibited signaling through erbBs, the receptor tyrosine kinase that transduces the effects of endogenous NRGs. Adult wildtype mice were treated with the small erbB receptor tyrosine kinase inhibitor PD158780 (330.18 Da; for erbB4, $\mathrm{IC}_{50}=52 \mathrm{nM}$; $10 \mathrm{mg} / \mathrm{kg}$, i.p., two times per day for $3 \mathrm{~d}$ starting at P90). Wholecell recordings of pharmacologically isolated mEPSCs in slices of 
A

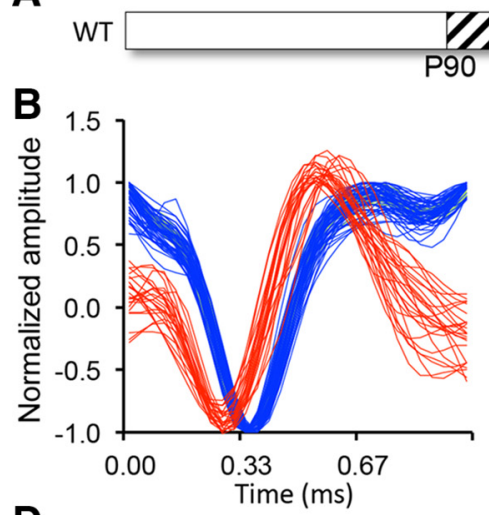

D

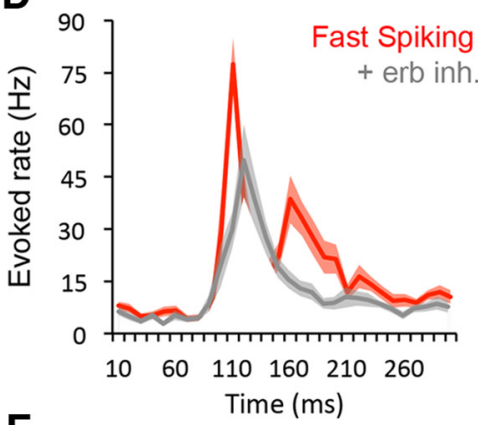

$\mathbf{F}$

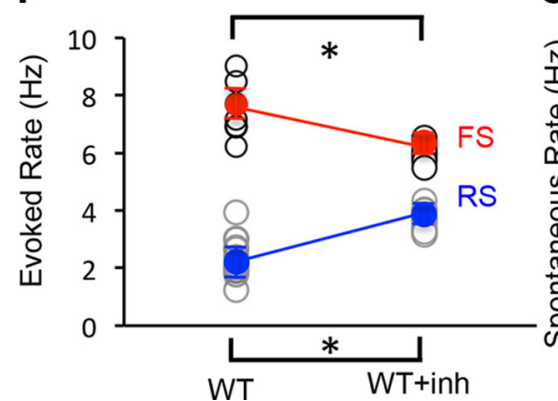

erb inh.

\section{$\mathrm{C}$}

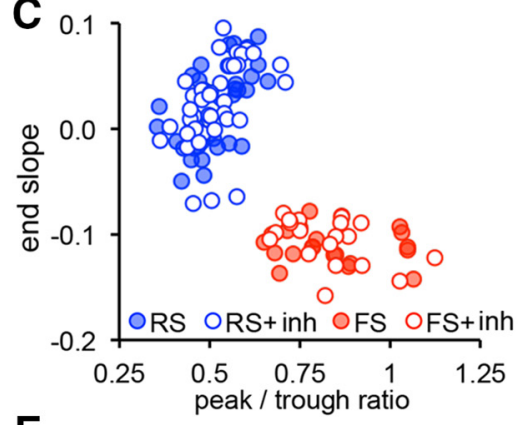

E

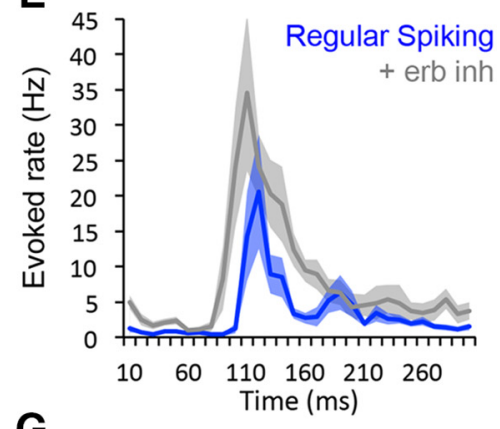

$\mathbf{G}$

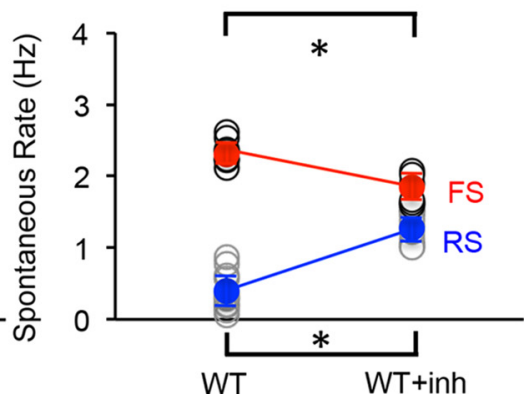

Figure 6. erbB inhibition decreases excitability of FS INs in vivo. $\boldsymbol{A}$, Experimental schematic. Treatment with the ErbB inhibitor (erb inh.) was initiated on P90. B, C, The treatment does not change the characteristics of single-unit waveforms $(\boldsymbol{B})$ or the sorting into two clusters based on waveform characteristics (C; red, FS; blue, RS). $\boldsymbol{D}, \boldsymbol{E}$, Average \pm SEM poststimulus time histograms for fast-spiking (red) and regular-spiking (blue) neurons in binocular visual cortex before and after treatment with the erbB inhibitor. Activity was evoked with $100 \%$ contrast, 0.05 cycles $/{ }^{\circ}$ gratings reversing at $1 \mathrm{~Hz}$. $\boldsymbol{F}, \mathbf{G}$, Significant difference in average visually evoked $(\boldsymbol{F})$ and spontaneous $(\boldsymbol{G})$ spike rates in FS (red) and RS (blue) neurons before and after treatment. Activity was averaged over 500 ms. Lines connect group averages. ${ }^{*} p<0.05, t$ test.

visual cortex prepared from G42 mice revealed that treatment with the erbB inhibitor significantly decreased the amplitudes, but not the frequencies, of mEPSCs onto layer 2/3 PV INs (Fig. 5).

To determine whether erbB inhibition could be used to control excitability of FS INs in vivo, PD158780 was delivered to adult wild-type mice. A single dose of the erbB inhibitor $(10 \mathrm{mg} / \mathrm{kg}$, i.p.) induced a $25.1 \pm 2.2 \%$ decrease in spontaneous firing frequency of FS INs within $15 \mathrm{~min}$ of delivery $(n=3$; data not shown). Longer-duration treatment with PD158780 (10 mg/kg, i.p., two times per day for $3 \mathrm{~d}$ starting at P90) did not impact waveform characteristic of the clustering of single units acquired from layer $2 / 3$ based on waveform parameters (Fig. $6 A-C$; RS, $n=34,8$; +inh, $n=32,8$; FS, $n=20,8$; +inh, $n=18,8)$. However, inhibition of erbB significantly decreased the excitability of FS INs (average \pm SEM, evoked, $2.38 \pm 0.20$; + inh, $3.65 \pm$ 0.11 ; spontaneous, $0.39 \pm 0.07$; + inh, $1.31 \pm 0.06$; Fig. $6 D, F$ ) and increased the excitability of RS neurons (evoked, 7.52 \pm 0.34 ;

+ inh, $6.05 \pm 0.13$; spontaneous, $2.34 \pm$ 0.06; +inh, $1.79 \pm 0.07$; Fig. $6 E, G)$. To determine how decreasing the excitability of FS INs in adults impacted ocular dominance plasticity, we examined the effect of erbB inhibition on the response to concurrent brief ( $3 \mathrm{~d}$ ) monocular deprivation initiated at P90 (Fig. 7A,B). Treatment with the erbB inhibitor enabled a shift in VEP ocular dominance in response to brief $\mathrm{MD}$, which is not seen at this age in the absence of PD158780 [ ${ }^{*} \mathrm{H}(2)=15.24$, $p<0.001$, Kruskal-Wallis test; Fig. 7C]. Thus, inhibition of erbB reactivated the critical period for ocular dominance plasticity.

\section{ErbB inhibition enables recovery from chronic monocular deprivation in adults}

The developmental reduction in ocular dominance plasticity is thought to limit the ability of adults to recover from the amblyopia. To determine whether erbB inhibition could be used to reverse the effects of long-term monocular deprivation, subjects received PD158780 (10 mg/ $\mathrm{kg}$, i.p., two times per day for $3 \mathrm{~d}$ starting at P90) after monocular deprivation from P14 to P90 (Fig. 8A). Single-unit activity from layer $2 / 3$ of binocular visual cortex revealed that ErbB inhibition decreased the excitability of FS INs (red; average \pm SEM evoked: cMD, $6.61 \pm 0.09, n=18,8$; + inh, $4.93 \pm 0.17, n=16,8$; spontaneous: cMD, $1.85 \pm 0.06$; + inh, $1.25 \pm 0.06$; Fig. $8 B, D$ ) and increased the excitability of RS neurons (evoked: cMD, $1.62 \pm 0.09$, $n=38,8$; + inh, $3.21 \pm 0.21, n=32,8$; spontaneous: cMD, $0.20 \pm 0.02 ;+$ inh, $1.09 \pm 0.08$; Fig. $8 C, E$ ). To ask whether decreasing the excitability of FS INs enabled recovery from chronic $\mathrm{MD}$, treatment with erbB inhibitor was initiated at eye opening at P90 (open, deprived eye; filled, nondeprived eye; Fig. $8 F-H$ ). Eye opening alone did not produce spontaneous recovery of ocular dominance; however, recovery of normal ocular dominance was enabled by treatment with PD158780 (10 mg/kg, i.p., two times per day for $3 \mathrm{~d}$ starting at P90) initiated at eye opening $\left[{ }^{*} \mathrm{H}(2)=\right.$ 15.37, $p<0.001$; Kruskal-Wallis test; Fig. $8 G, H]$. Thus, a reduction in excitability of FS INs was sufficient to reactivate plasticity in the adult visual cortex and enable recovery from chronic monocular deprivation.

\section{Discussion}

Fast-spiking interneurons in the visual cortex exert powerful control over pyramidal neuron excitability and plasticity. Here we show that the NRG/erbB signaling pathway controls the strength of excitation onto FS INs, and can be manipulated to reversibly regulate ocular dominance plasticity. Treatment with the neurotrophin NRG1 increases the excitability of FS INs; however, the impact of this increase depends on the initial state of 
excitatory input. During the critical period, when excitation onto FS INs is predicted to be optimal, NRG1 treatment induced a precocious termination of the critical period. In contrast, in NARP ${ }^{-1-}$ mice, in which reduced excitatory drive onto FS INs prevents the initiation of the critical period, NRG1 treatment rescues FS IN excitability and ocular dominance plasticity. Importantly, the reactivation of the critical period in adults by dark exposure was reversed by NRG1 treatment, suggesting that dark exposure reduces excitation onto FS INs into a range permissible for ocular dominance plasticity. In addition, NRG/erbB4-dependent maintenance of excitation onto FS INs plays a fundamental role in the active constraint of plasticity in the adult visual cortex. Conditional deletion of erbB4 in PV + interneurons reduces the excitability of FS INs and renders the visual cortex insensitive to regulation by NRG1. Inhibition of endogenous NRG signaling in adults, via inhibition of erbB, decreases the excitability of FS INs and reactivates the critical period for ocular dominance plasticity.

The decrease in FS IN excitability mediated by inhibition of erbB is sufficient for recovery from long-term monocular deprivation, reinforcing the idea that the developmental loss of plasticity limits the recovery from amblyopia in adulthood. This work demonstrates that the strength of excitation onto FS INs is an important locus for bidirectional control of critical period plasticity and identifies NRG/erbB4 signaling as a target for therapeutic enhancement of plasticity in adults.

\section{Role of excitation onto FS INs in the response to MD}

A decrease in the amplitude and frequency of mEPSCs in FS INs is an early response to monocular deprivation in young mice at the peak of the critical period for ocular dominance plasticity (Kuhlman et al. 2013). The decrease in FS IN excitability would enable the enhancement of excitability of downstream RS neurons necessary to engage spike-timing-dependent mechanisms of synaptic plasticity. A developmental slowing of plasticity at excitatory synapses onto FS INs may explain the requirement for longer durations of monocular deprivation with age (Sawtell et al., 2003; Pham et al., 2004; Lehmann and Löwel, 2008; Huang et al., 2010; Kameyama et al., 2010). Indeed, the rapid decrease in excitation onto FS INs induced by monocular deprivation is lost relatively early in development, at ages where ocular dominance plasticity can be engaged by longer durations of MD. The dependence on erbB4 for the maintenance of excitatory synapses onto FS INs appears to also increase with age, as mEPSCs recorded from PV+ FS INs in the prefrontal cortex of erbB4 ${ }^{-1-}$ mice are normal at P21 but are reduced later in development (Yang et al., 2013). Direct reduction of the strength of excitation onto FS INs via erbB inhibitions in adults reactivates plasticity and may compensate for the developmental loss of plasticity at these synapses

\section{Parallel pathways for the regulation of excitatory synaptic strength on FS INs}

A subset of signaling pathways that regulate synapse strength and number are highly enriched at excitatory synapses onto FS INs.
The two pathways examined here, NRG/erbB4 and NARP, have both been shown to regulate the stability of AMPARs at excitatory synapses onto FS INs, albeit by different mechanisms. erbB4 and NARP are also targets for signaling pathways that enable rapid plasticity at these synapses (Cho et al., 2008; Chang et al., 2010; Tamura et al., 2012; Vullhorst et al., 2015). NARP [also known as NP2 (neural pentraxin 2)] forms an AMPAR-binding complex with NP1 (neuronal pentraxin 1) and NPR (neuronal pentraxin receptor; O'Brien et al., 1999; $\mathrm{Xu}$ et al., 2003), enabling coregulation of GluR4-containing AMPARs and surface NARP expression (Chang et al., 2010; Pelkey et al., 2015). In contrast, NRG is thought to induce a tyrosine kinase-dependent stabilization of PSD-95 and subsequent recruitment or maintenance of synaptic AMPARs (Li et al., 2007; Ting et al., 2011). In addition to the relatively rapid increase in mEPSC amplitudes onto FS INs observed by us and others in response to NRG1 treatment in cortex [Abe et al., 2011; but see Fazzari et al. (2010) regarding hippocampus], a slower latency increase in excitatory synapse number has been observed in response to manipulations of NRG/erb signaling. Accordingly, long-term treatment with NRG1 results in a delayed increase in the frequencies of mEPSCs in FS INs, and decreased mEPSC frequencies by erbB4 deletion emerges late in development (Abe et al., 2011; Yang et al., 2013).

However, a single dose of NRG1 has also been shown to reduce the excitability and increase the action potential threshold in erbB4+ hippocampal neurons (Janssen et al., 2012). Activation of erbB4 also induces the internalization of $\alpha 1$-containing GABA receptors and GluN2b-containing NMDARs in hippocampal interneurons identified by live labeling with erbB4 antibody (Mitchell et al., 2013; Vullhorst et al., 2015), which would increase the excitability of erbB4+ interneurons and enhance the stability of excitatory synapses. Our demonstration that NRG1 treatment can rescue the deficits of the $\mathrm{NARP}^{-1-}$ mice, including a reversal of FS IN hypoexcitability and a recovery of ocular dominance plasticity, supports the independence of these signaling path- 


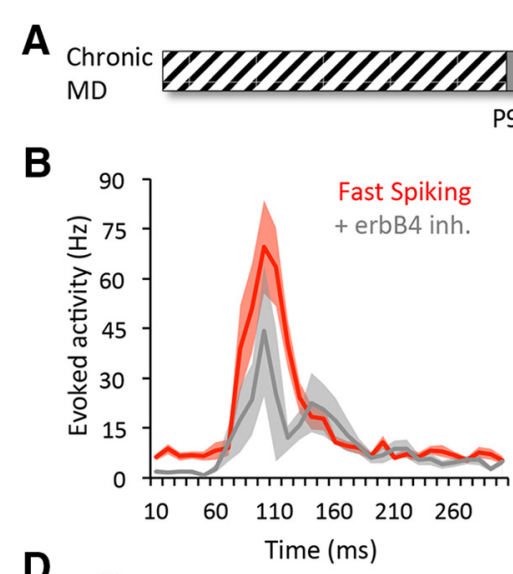

D
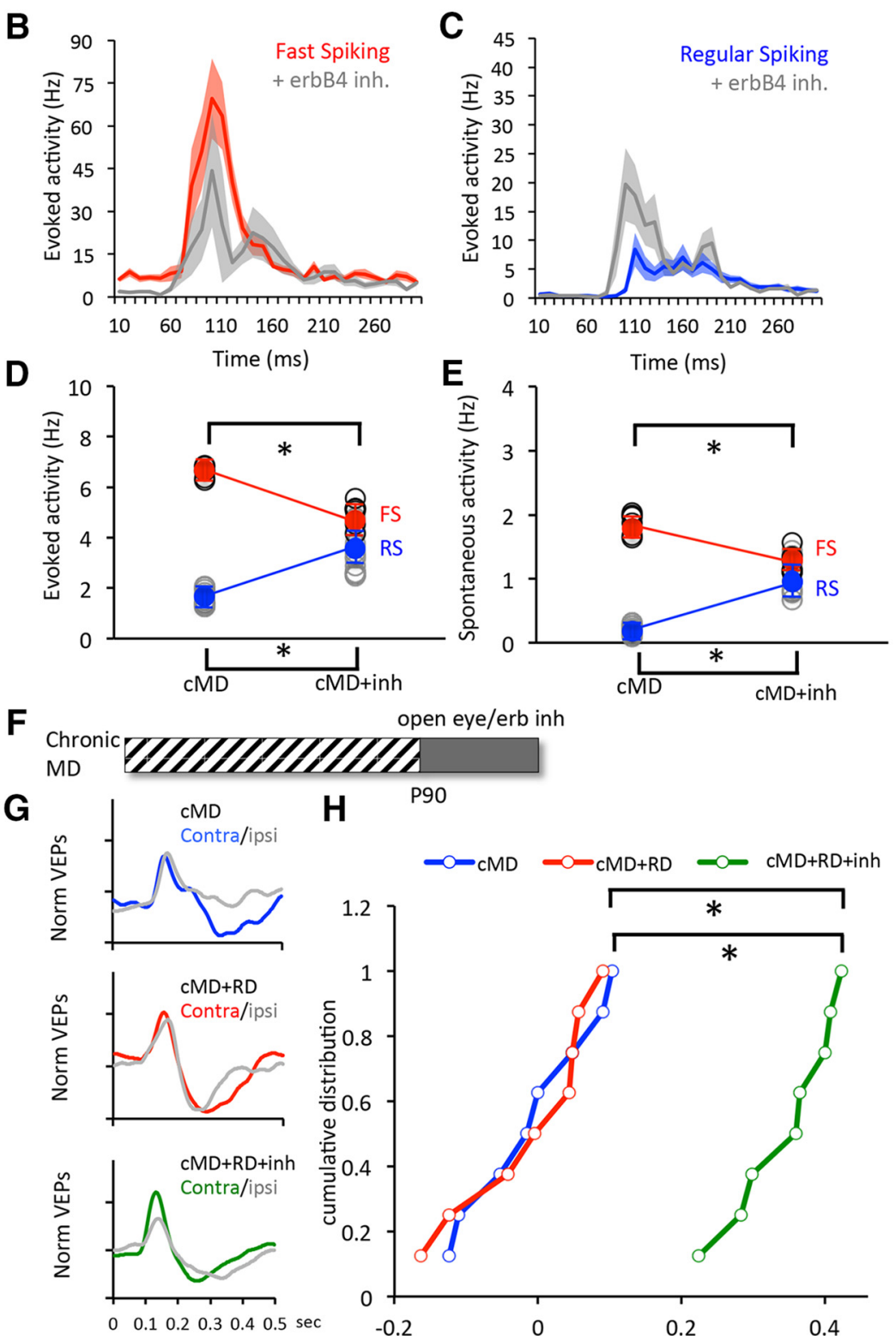

$\mathrm{H}$

open eye/erb inh

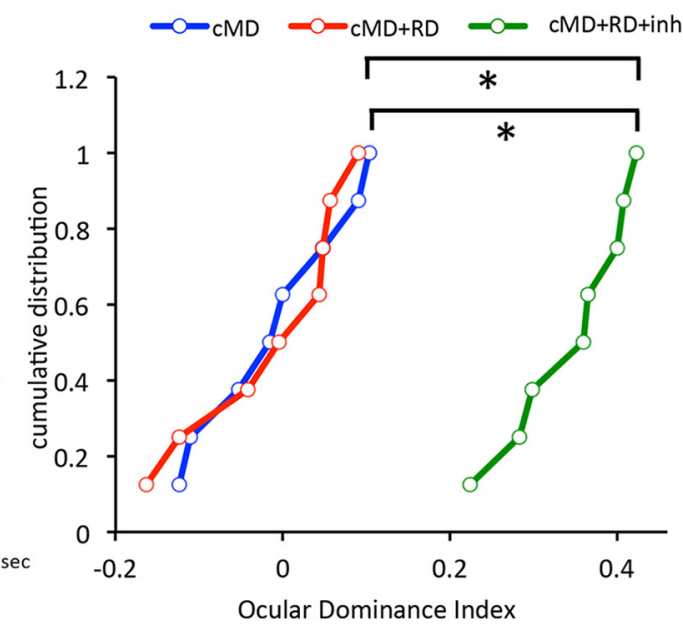

Figure 8. ErbB inhibition allows for recovery from amblyopia in adults. $A$, Experimental schematic. Subjects received monocular deprivation from eye opening ( P P14) until adulthood (P90), followed by treatment with ErbB inhibitor ( 3 d). B, C, Average \pm SEM poststimulus time histograms for fast-spiking ( $\boldsymbol{B}$, red) and regular-spiking $(\boldsymbol{C}$, blue) neurons in deprived visual cortex before and after treatment with erbB inhibitor. Activity was evoked with $100 \%$ contrast, 0.05 cycles $/{ }^{\circ}$ gratings reversing at $1 \mathrm{~Hz}$. D, E, Significant difference in average visually evoked (D) and spontaneous $(\boldsymbol{E})$ spike rates in $\mathrm{FS}$ (red) and RS (blue) neurons before and after treatment. Activity was averaged over $500 \mathrm{~ms}$. Lines connect group averages. ${ }^{*} p<0.05, t$ test. $\boldsymbol{F}$, Experimental schematic. Subjects received monocular deprivation from eye opening until adulthood, followed by treatment with the ErbB inhibitor and concurrent reverse deprivation (open, the closed eye; filled, the open eye, $3 \mathrm{~d}$ ). G, Average VEP waveforms in response to stimulation of contralateral (Contra) and ipsilateral (Ipsi) eye after chronic MD (top), chronicMD followed by reverse deprivation (middle), and chronic MD followed by reverse deprivation with erbB inhibition (bottom). $\boldsymbol{H}$, Cumulative distributions of ODIs. The erbB inhibition (green) enabled a significant recovery from chronic monocular deprivation (green). ${ }^{*} p<0.001$; Kruskal-Wallis test, $\mathrm{H}(2)=15.37$.

ways. Interestingly, NRG/erbB4 and NARP/NPR complexes both interact with molecules of perineuronal nets, dense specializations of the extracellular matrix that surround FS INs, suggesting a possible locus for coregulation of these pathways.

\section{Distribution of erbB4 in mammalian cortex}

Our demonstration of the enrichment of erbB4 receptors in parvalbumin ${ }^{+}$interneurons in the mouse visual cortex confirms and extends previous reports of the selectivity of erbB4 expression (Fazzari et al., 2010; Neddens and Buonanno, 2010; Bean et al., 2014; Lu et al., 2014). Although we cannot rule out the possibility of indirect effects, our data strongly support that peripheral delivery of NRG1 directly activates cortical erbB4 receptors to increase FS IN excitability. Indeed, a single low dose of the small (71 amino acid) NRG1 peptide significantly increased the phosphorylation of cortical erbB4 receptors, a traditional measure of NRG1 influx into the brain (Rösler et al., 2011). Previous work has demonstrated that radiolabeled NRG1 delivered peripherally can be detected in brain within 15 min of a single injection, with no changes in $T_{\max }$ detected from $20 \mathrm{~min}$ to $4 \mathrm{~h}$ after injection (Rösler et al., 2011; Li Y et al., 2012). The influx of radiolabeled NRG1 into brain is saturable (reduced by inclusion of nonradiolabeled NRG1-1 peptide) and blocked by antibodies to NRG1 receptors (Kastin et al., 2004), suggesting that NRG1 crosses the blood-brain barrier through receptor-mediated transport. Importantly, the effects of repeated injections of low-dose NRG1 that we observe, including the increase in MEPSC amplitudes recorded in FS INs and the increase in FS IN excitability recorded in vivo, were absent in the visual cortex of PV-erbB4 $4^{-1-}$ mice. Similar treatments with the small NRG1 peptide protects central neurons from toxic insults (Carlsson et al., 2011; Li KX et al., 2012; Depboylu et al., 2015). In the absence of erbB4, the baseline excitability of FS INs was significantly reduced, reinforcing the idea that the NRG1/erbB4 signaling pathway plays an important role in the maintenance of excitatory drive onto this class of interneuron.

\section{Reactivation of the critical period in adulthood}

Our demonstration that inhibition of erbBs reactivates the critical period for ocular dominance plasticity supports a model in which plasticity in adults is actively constrained by maintenance of strong excitation onto FS INs. Accordingly, dark exposure, which reactivates robust ocular dominance plasticity in adult mice, reduces the excitability of FS INs. Indeed, a reduction in the excitability of FS INs may be a mechanism common to several manipulations that reactivate the critical period in adulthood. For example, environ- 
mental enrichment, shown to reactivate robust ocular dominance plasticity in adults, reduces the expression of parvalbumin and GAD67 in inhibitory neurons of the visual cortex, indicative of a reduction in excitability (Sale et al., 2007; Donato et al., 2013). Similarly, treatment with the antidepressant fluoxetine, which reactivates rapid ocular dominance plasticity in adults, decreases the expression of PV in the visual cortex and decreases the number of perineuronal nets that colocalize with $\mathrm{PV}+$ interneurons (Maya Vetencourt et al., 2008; Guirado et al., 2014). Fluoxetine also accelerates morphological plasticity of inhibitory dendrites induced by monocular deprivation (Chen et al., 2011). Thus, the strength of excitation onto FS INs is a key site for the regulation of the critical period, and NARP and NRG signaling complexes are emerging as powerful and reversible regulators of the strength of these synapses.

\section{References}

Abe Y, Namba H, Kato T, Iwakura Y, Nawa H (2011) Neuregulin-1 signals from the periphery regulate AMPA receptor sensitivity and expression in GABAergic interneurons in developing neocortex. J Neurosci 31:56995709. CrossRef Medline

Bean JC, Lin TW, Sathyamurthy A, Liu F, Yin DM, Xiong WC, Mei L (2014) Genetic labeling reveals novel cellular targets of schizophrenia susceptibility gene: distribution of GABA and non-GABA ErbB4-positive cells in adult mouse brain. J Neurosci 34:13549-13566. CrossRef Medline

Carlsson T, Schindler FR, Höllerhage M, Depboylu C, Arias-Carrión O, Schnurrbusch S, Rösler TW, Wozny W, Schwall GP, Groebe K, Oertel WH, Brundin P, Schrattenholz A, Höglinger GU (2011) Systemic administration of neuregulin- $1 \beta 1$ protects dopaminergic neurons in a mouse model of Parkinson's disease. J Neurochem 117:1066-1074. CrossRef Medline

Chang MC, Park JM, Pelkey KA, Grabenstatter HL, Xu D, Linden DJ, Sutula TP, McBain CJ, Worley PF (2010) Narp regulates homeostatic scaling of excitatory synapses on parvalbumin-expressing interneurons. Nat Neurosci 13:1090-1097. CrossRef Medline

Chen JL, Lin WC, Cha JW, So PT, Kubota Y, Nedivi E (2011) Structural basis for the role of inhibition in facilitating adult brain plasticity. Nat Neurosci 14:587-594. CrossRef Medline

Cho RW, Park JM, Wolff SB, Xu D, Hopf C, Kim JA, Reddy RC, Petralia RS, Perin MS, Linden DJ, Worley PF (2008) mGluR1/5-dependent longterm depression requires the regulated ectodomain cleavage of neuronal pentraxin NPR by TACE. Neuron 57:858-871. CrossRef Medline

Depboylu C, Rösler TW, de Andrade A, Oertel WH, Höglinger GU (2015) Systemically administered neuregulin- $1 \beta 1$ rescues nigral dopaminergic neurons via the ErbB4 receptor tyrosine kinase in MPTP mouse models of Parkinson's disease. J Neurochem 133:590-597. CrossRef Medline

Di Cristo G, Chattopadhyaya B, Kuhlman SJ, Fu Y, Bélanger MC, Wu CZ, Rutishauser U, Maffei L, Huang ZJ (2007) Activity-dependent PSA expression regulates inhibitory maturation and onset of critical period plasticity. Nat Neurosci 10:1569-1577. CrossRef Medline

Donato F, Rompani SB, Caroni P (2013) Parvalbumin-expressing basketcell network plasticity induced by experience regulates adult learning. Nature 504:272-276. CrossRef Medline

Eaton NC, Sheehan HM, Quinlan EM (2016) Optimization of visual training for full recovery from severe amblyopia in adults. Learn Mem 23: 99-103. CrossRef Medline

Fagiolini M, Hensch TK (2000) Inhibitory threshold for critical-period activation in primary visual cortex. Nature 404:183-186. CrossRef Medline

Fazzari P, Paternain AV, Valiente M, Pla R, Luján R, Lloyd K, Lerma J, Marín O, Rico B (2010) Control of cortical GABA circuitry development by Nrg1 and ErbB4 signaling. Nature 464:1376-1380. CrossRef Medline

Gu Y, Huang S, Chang MC, Worley P, Kirkwood A, Quinlan EM (2013) Obligatory role for the immediate early gene NARP in critical period plasticity. Neuron 79:335-346. CrossRef Medline

Guo Y, Huang S, de Pasquale R, McGehrin K (2012) Dark exposure extends the integration window for spike-timing-dependent plasticity. J Neurosci 32:15027-15035. CrossRef Medline

Guirado R, Perez-Rando M, Sanchez-Matarredona D, Castrén E, Nacher J (2014) Chronic fluoxetine treatment alters the structure, connectivity and plasticity of cortical interneurons. Int J Neuropsychopharmacol 17: 1635-1646. CrossRef Medline

He HY, Ray B, Dennis K, Quinlan EM (2007) Experience-dependent recovery of vision following chronic deprivation amblyopia. Nat Neurosci 10: 1134-1136. CrossRef Medline

Huang S, Gu Y, Quinlan EM, Kirkwood A (2010) A refractory period for rejuvenating GABAergic synaptic transmission and ocular dominance plasticity with dark exposure. J Neurosci 30:16636-16642. CrossRef Medline

Huang ZJ, Kirkwood A, Pizzorusso T, Porciatti V, Morales B, Bear MF, Maffei L, Tonegawa S (1999) BDNF regulates the maturation of inhibition and the critical period of plasticity in mouse visual cortex. Cell 98:739-755. CrossRef Medline

Janssen MJ, Leiva-Salcedo E, Buonanno A (2012) Neuregulin directly decreases voltage-gated sodium current in hippocampal ErbB4-expressing interneurons. J Neurosci 32:13889-13895. CrossRef Medline

Kameyama K, Sohya K, Ebina T, Fukuda A, Yanagawa Y, Tsumoto T (2010) Difference in binocularity and ocular dominance plasticity between GABAergic and excitatory cortical neurons. J Neurosci 30:1551-1559. CrossRef Medline

Kastin AJ, Akerstrom V, Pan W (2004) Neuregulin-1-betal enters brain and spinal cord by receptor-mediated transport. J Neurochem 88:965-970. CrossRef Medline

Kirkpatrick LL, Matzuk MM, Dodds DC, Perin MS (2000) Biochemical interactions of the neuronal pentraxins. Neuronal pentraxin (NP) receptor binds to taipoxin and taipoxin-associated calcium-binding protein 49 via NP1 and NP2. J Biol Chem 275:17786-17792. CrossRef Medline

Krishnan K, Wang BS, Lu J, Wang L, Maffei A, Cang J, Huang ZJ (2015) $\mathrm{MeCP} 2$ regulates the timing of critical period plasticity that shapes functional connectivity in primary visual cortex. Proc Natl Acad Sci U S A 112:E4782-E4791. CrossRef Medline

Kuhlman SJ, Olivas ND, Tring E, Ikrar T, Xu X, Trachtenberg JT (2013) A disinhibitory microcircuit initiates critical-period plasticity in the visual cortex. Nature 501:543-546. CrossRef Medline

Lehmann K, Löwel S (2008) Age-dependent ocular dominance plasticity in adult mice. PLoS One 3:e3120. CrossRef Medline

Li B, Woo RS, Mei L, Malinow R (2007) The neuregulin-1 receptor erbB4 controls glutamatergic synapse maturation and plasticity. Neuron 54: 583-597. CrossRef Medline

Li KX, Lu YM, Xu ZH, Zhang J, Zhu JM, Zhang JM, Cao SX, Chen XJ, Chen Z, Luo JH, Duan S, Li XM (2012) Neuregulin 1 regulates excitability of fast-spiking neurons through Kv1.1 and acts in epilepsy. Nat Neurosci 15:267-273. CrossRef Medline

Li Y, Lein PJ, Liu C, Bruun DA, Giulivi C, Ford GD, Tewolde T, Ross-Inta C, Ford BD (2012) Neuregulin-1 is neuroprotective in a rat model of organophosphate-induced delayed neuronal injury. Toxicol Appl Pharmacol 262:194-204. CrossRef Medline

Lu Y, Sun XD, Hou FQ, Bi LL, Yin DM, Liu F, Chen YJ, Bean JC, Jiao HF, Liu X, Li BM, Xiong WC, Gao TM, Mei L (2014) Maintenance of GABAergic activity by neuregulin 1-ErbB4 in amygdala for fear memory. Neuron 84:835-846. CrossRef Medline

Maya Vetencourt JF, Sale A, Viegi A, Baroncelli L, De Pasquale R, O’Leary OF, Castrén E, Maffei L (2008) The antidepressant fluoxetine restores plasticity in the adult visual cortex. Science 320:385-388. CrossRef Medline

Mei L, Nave KA (2014) Neuregulin-ERBB signaling in the nervous system and neuropsychiatric diseases. Neuron 83:27-49. CrossRef Medline

Mitchell RM, Janssen MJ, Karavanova I, Vullhorst D, Furth K, Makusky A, Markey SP, Buonanno A (2013) ErbB4 reduces synaptic GABA currents independent of its receptor tyrosine kinase activity. Proc Natl Acad Sci U S A 110:19603-19608. CrossRef Medline

Montey KL, Quinlan EM (2011) Recovery from chronic monocular deprivation following reactivation of thalamocortical plasticity by dark exposure. Nat Commun 2:317. CrossRef Medline

Neddens J, Buonanno A (2010) Selective populations of hippocampal interneurons express ErbB4 and their number and distribution is altered in ErbB4 knockout mice. Hippocampus 20:724-744. CrossRef Medline

Niell CM, Stryker MP (2008) Highly selective receptive fields in mouse visual cortex. J Neurosci 28:7520-7536. CrossRef Medline

O’Brien RJ, Xu D, Petralia RS, Steward O, Huganir RL, Worley P (1999) Synaptic clustering of AMPA receptors by the extracellular immediateearly gene product Narp. Neuron 23:309-323. CrossRef Medline

Pelkey KA, Barksdale E, Craig MT, Yuan X, Sukumaran M, Vargish GA, 
Mitchell RM, Wyeth MS, Petralia RS, Chittajallu R, Karlsson RM, Cameron HA, Murata Y, Colonnese MT, Worley PF, McBain CJ (2015) Pentraxins coordinate excitatory synapse maturation and circuit integration of parvalbumin interneurons. Neuron 85:1257-1272. CrossRef Medline

Penzes P, Buonanno A, Passafaro M, Sala C, Sweet RA (2013) Developmental vulnerability of synapses and circuits associated with neuropsychiatric disorders. J Neurochem 126:165-182. CrossRef Medline

Pham TA, Graham SJ, Suzuki S, Barco A, Kandel ER, Gordon B, Lickey ME (2004) A semi-persistent adult ocular dominance plasticity in visual cortex is stabilized by activated CREB. Learn Mem 11:738-747. CrossRef Medline

Pitcher GM, Kalia LV, Ng D, Goodfellow NM, Yee KT, Lambe EK, Salter MW (2011) Schizophrenia susceptibility pathway neuregulin 1-ErbB4 suppresses Src upregulation of NMDA receptors. Nat Med 17:470-478. CrossRef Medline

Rico B, Marín O (2011) Neuregulin signaling, cortical circuitry development and schizophrenia. Curr Opin Genet Dev 21:262-270. CrossRef Medline

Rösler TW, Depboylu C, Arias-Carrión O, Wozny W, Carlsson T, Höllerhage M, Oertel WH, Schrattenholz A, Höglinger GU (2011) Biodistribution and brain permeability of the extracellular domain of neuregulin-1- $\beta 1$. Neuropharmacology 61:1413-1418. CrossRef Medline

Sale A, Maya Vetencourt JF, Medini P, Cenni MC, Baroncelli L, De Pasquale R, Maffei L (2007) Environmental enrichment in adulthood promotes amblyopia recovery through a reduction of intracortical inhibition. Nat Neurosci 10:679-681. CrossRef Medline

Sawtell NB, Frenkel MY, Philpot BD, Nakazawa K, Tonegawa S, Bear MF (2003) NMDA receptor-dependent ocular dominance plasticity in adult visual cortex. Neuron 38:977-985. CrossRef Medline

Scott LL, Kogan D, Shamma AA, Quinlan EM (2010) Differential regulation of synapsin phosphorylation by monocular deprivation in juveniles and adults. Neuroscience 166:539-550. CrossRef Medline

Shamir A, Kwon OB, Karavanova I, Vullhorst D, Leiva-Salcedo E, Janssen MJ, Buonanno A (2012) The importance of the NRG-1/ErbB4 pathway for synaptic plasticity and behaviors associated with psychiatric disorders. J Neurosci 32:2988-2997. CrossRef Medline

Takesian AE, Hensch TK (2013) Balancing plasticity/stability across brain development. Prog Brain Res 207:3-34. CrossRef Medline

Tamura H, Kawata M, Hamaguchi S, Ishikawa Y, Shiosaka S (2012) Processing of neuregulin-1 by neuropsin regulates GABAergic neuron to control neural plasticity of the mouse hippocampus. J Neurosci 32: 12657-12672. CrossRef Medline

Taniguchi H, Lu J, Huang ZJ (2013) The spatial and temporal origin of chandelier cells in mouse neocortex. Science 339:70-74. CrossRef Medline

Ting AK, Chen Y, Wen L, Yin DM, Shen C, Tao Y, Liu X, Xiong WC, Mei L (2011) Neuregulin 1 promotes excitatory synapse development and function in GABAergic interneurons. J Neurosci 31:15-25. CrossRef Medline

Vullhorst D, Mitchell RM, Keating C, Roychowdhury S, Karavanova I, TaoCheng JH, Buonanno A (2015) A negative feedback loop controls NMDA receptor function in cortical interneurons via neuregulin 2/ErbB4 signalling. Nat Commun 6:7222. CrossRef Medline

Xu D, Hopf C, Reddy R, Cho RW, Guo L, Lanahan A, Petralia RS, Wenthold RJ, O'Brien RJ, Worley P (2003) Narp and NP1 form heterocomplexes that function in developmental and activity-dependent synaptic plasticity. Neuron 39:513-528. CrossRef Medline

Yang JM, Zhang J, Chen XJ, Geng HY, Ye M, Spitzer NC, Luo JH, Duan SM, Li XM (2013) Development of GABA circuitry of fast-spiking basket interneurons in the medial prefrontal cortex of erbb4-mutant mice J Neurosci 33:19724-19733. CrossRef 